\title{
PRESENTACIÓN
}

\section{TIEMPO DE DEFINICIONES: \\ MAXIMILIANO EN MÉXICO}

$\mathrm{E}_{\text {del archiduque austriaco, Maximiliano de Habsburgo, }}$ y su esposa Carlota a la ciudad de México. Venían, al abrigo de las armas de un ejército invasor, a ocupar un trono al que los habían llamado los conservadores derrotados en la guerra civil. Durante largo tiempo, los historiadores hicieron de su gobierno (1864-1867) la misma crónica superficial y acartonada. El Imperio, contrapunto de la heroica resistencia republicana que dio derecho a México de, en palabras de Justo Sierra, "llamarse nación", se presentaba como un episodio ridículo e intrascendente, en el que pesaban más la ambición de Napoleón y los desmanes del ejército expedicionario que los proyectos y políticas del desafortunado príncipe. A siglo y medio de distancia, podemos decir que la mirada historiográfica sobre el Segundo Imperio mexicano se ha revaluado.

Así lo demostró el coloquio que, para conmemorar los inicios del régimen imperial, organizaron la Facultad de Filosofía y Letras de la Universidad Nacional Autónoma 
de México y el Centro de Estudios Históricos de El Colegio de México en mayo de 2014, y del cual los artículos que siguen son una muestra. Quienes participaron en esta reunión académica abordaron este periodo de la historia de México, exponiendo tanto sus peculiaridades como las continuidades que lo vinculan con los años que lo precedieron y siguieron. Asimismo tomaron en cuenta la naturaleza transnacional de muchos de los procesos que le dieron forma, recordando que la década de 1860 fue un "tiempo de definiciones" no sólo para México sino para prácticamente todo el mundo, donde se dirimió la disyuntiva monarquía/república, característica de la política posrevolucionaria liberal. A ello se sumó la transformación del capitalismo, y el que varias potencias europeas se lanzaron a la construcción de nuevos imperios, articulados en torno a intereses, mecanismos y discursos distintos a los que habían apuntalado a los imperios atlánticos que se desarticularon con las revoluciones "liberales".

Así, la búsqueda de un régimen político estable, que desde finales del siglo xviII había caracterizado a muchos estados, llevó a un grupo importante de políticos mexicanos - conservadores y liberales moderados - a apostar por un gobierno monárquico; pero de igual forma a los franceses a abandonar a la República que con tanto entusiasmo habían aclamado en febrero de 1848, para poner sobre el trono al sobrino de Napoleón, al tiempo que las élites japonesas se impusieron reforzar la autoridad del emperador e impulsar una industrialización acelerada. Asimismo, como puede leerse más adelante, las posibilidades de la monarquía - forma

${ }^{1}$ Véase el sugerente artículo de BECKERT, “Emancipation”. 
de gobierno que se piensa era, para la segunda mitad del siglo xIx, considerada vetusta, polvosa y retardataria - sedujeron, de manera predecible quizá, al paladín del conservadurismo ecuatoriano, Gabriel García Moreno, pero también, aunque ciertamente de forma fugaz y coyuntural, a uno de los paladines del liberalismo argentino, Juan Bautista Alberdi.

Los artículos del presente número dan cuenta de los complejos procesos que sirvieron de marco al Segundo Imperio mexicano y de la renovación historiográfica en torno de ellos. Paul Garner analiza las formas en que los historiadores británicos describieron la construcción y funcionamiento del más imponente de los imperios finiseculares: el que presidió, desde Londres y durante más de 60 años, la reina Victoria. Cotejar las categorías analíticas y propuestas teóricas con la experiencia británica en la que fuera una región marginal para el imperialismo inglés - Latinoamérica en general, y México en particular - permite a Garner esbozar los alcances y límites de estos enfoques.

Por su parte, Ana Buriano y Horacio Crespo exploran las repercusiones de la intervención de Francia en México y del Imperio de Maximiliano en los horizontes de posibilidad de los proyectos políticos en lo que, a partir de entonces, empezó a llamarse América "Latina". Buriano analiza los planes de García Moreno para Ecuador - primero el protectorado francés y luego la "República del Sagrado Corazón” - entre 1861 y 1875, que si bien fueron contradictorios, reflejan el desencanto y cansancio de las élites ecuatorianas ante la anarquía prevaleciente así como la búsqueda de un proyecto unificador $y$, en última instancia, nacionalista. Crespo, por su lado, muestra la valoración, en muchos sentidos sorprendente, que hizo Alberdi de la monarquía, 
como una forma de gobierno que podía servir de baluarte de la libertad en las atormentadas naciones sudamericanas.

Laurence Coudart aborda la genealogía y evolución de la libertad de prensa durante el Segundo Imperio y muestra, con creces, las continuidades jurídicas y gubernativas del Estado mexicano en su afán de institucionalizar y afianzar su débil autoridad. Interroga no sólo las estrategias sino también los prismas y la representatividad política de una clase dirigente que no logra rebasar la lógica del estado de excepción y que posterga sin cesar el estado de derecho. En el espacio restringido y desigual que estructuraba esta legislación, la caricatura política desempeñó un papel central. Así, Alejandro de la Torre desmenuza su significado como vehículo de crítica política, cuyo simbolismo a un tiempo abrevaba de un imaginario transatlántico y respondía a la lógica del juego político nacional.

Pocas líneas de investigación sobre el siglo xIX mexicano se han enriquecido tanto en las últimas décadas como las que exploran el conflicto Iglesia Estado. ${ }^{2}$ Aquí, Elisa Cárdenas pone los sucesos mexicanos en el contexto de la "Iglesia universal” y de la política de Pío IX, pero también pondera su lugar, por medio de un juego de escalas, dentro de diversos ciclos temporales que parecen cerrarse en este momento. Finalmente, el artículo de Paolo Riguzzi y Francesco Gerali da cuenta de la política petrolera de Maximiliano de Habsburgo en el contexto del impulso petrolero de corte global generado por el surgimiento de la explotación moderna del crudo en Estados Unidos de América. Tema inexplorado

${ }^{2}$ Especialmente notables son los trabajos de Connaughton, Ideología; Entre la voz; Galeana, Las relaciones; García Ugarte, Poder. 
hasta el momento, el texto evalúa el papel que este episodio de mediados de la década de 1860 tuvo en el proceso de otorgamiento de un significado comercial al petróleo mexicano.

Creemos que los textos aquí reunidos reflejan el dinamismo de un campo historiográfico vigoroso y sugieren nuevas posibilidades para la investigación. Agradecemos a nuestros colegas el entusiasmo, la seriedad y el compromiso académico que manifiestan estos textos que contribuyen a la comprensión de un periodo poco explorado de nuestra historia.

\author{
ERIKa Pani \\ El Colegio de México \\ Antonia Pi-Suñer Llorens \\ Universidad Nacional Autónoma de México
}

REFERENCIAS

BECKERT, Sven

"Emancipation and Empire: Reconstructing the Worldwide Web of Cotton Production in the Age of the American Civil War", en American Historical Review, 109 (2004), pp. 1405-1438.

Connaughton, Brian

Ideología y sociedad en Guadalajara, 1788-1853: la Iglesia católica y la disputa por definer la nación mexicana, México, Conaculta, 2012.

Entre la voz de Dios y el llamado de la patria: religión, identidad y ciudadanía en México, siglo XIX, México, Fondo de Cultura Económica, Universidad Autónoma MetropolitanaIztapalapa, 2010. 
Galeana, Patricia

Las relaciones Iglesia-Estado durante el Segundo Imperio, México, Universidad Nacional Autónoma de México, 1991.

García Ugarte, Marta Eugenia

Poder político y religioso. México, siglo XIX, México, Miguel Ángel Porrúa, Universidad Nacional Autónoma de México, 2010, 2 volúmenes. 